\title{
Fermented Chinese Formula Shuan-Tong-Ling Protects Brain Microvascular Endothelial Cells against Oxidative Stress Injury
}

\author{
Lingjing Tan, ${ }^{1,2}$ Xiang Zhang, ${ }^{3}$ Zhigang Mei, ${ }^{1,2}$ Jinfeng Wang, ${ }^{1}$ Xiaoli Li, \\ Weifeng Huang, ${ }^{1}$ and Songbai Yang ${ }^{4}$ \\ ${ }^{1}$ Third-Grade Pharmacological Laboratory on Chinese Medicine Approved by State Administration of Traditional Chinese Medicine, \\ Medical College of China Three Gorges University, Yichang, Hubei 443002, China \\ ${ }^{2}$ Key Laboratory of Cardiovascular and Cerebrovascular Diseases Translational Medicine, \\ China Three Gorges University, Yichang, Hubei 443002, China \\ ${ }^{3}$ Yiling Hospital, Yichang, Hubei 443100, China \\ ${ }^{4}$ Yichang Hospital of Traditional Chinese Medicine, Clinical Medical College of Traditional Chinese Medicine, \\ China Three Gorges University, Yichang, Hubei 443003, China
}

Correspondence should be addressed to Zhigang Mei; meizhigang@ctgu.edu.cn

Received 31 July 2016; Revised 24 October 2016; Accepted 31 October 2016

Academic Editor: Ki-Wan Oh

Copyright (C) 2016 Lingjing Tan et al. This is an open access article distributed under the Creative Commons Attribution License, which permits unrestricted use, distribution, and reproduction in any medium, provided the original work is properly cited.

\begin{abstract}
Fermented Chinese formula Shuan-Tong-Ling (STL), composed of fourteen medicinal herbs, was an experiential formula by Dr. Zhigang Mei for treating vascular encephalopathy, but the underlying mechanisms remained unknown. In this study, we aimed to investigate the protective effects of fermented STL on hydrogen peroxide- $\left(\mathrm{H}_{2} \mathrm{O}_{2}^{-}\right)$induced injury in rat brain microvascular endothelial cells (BMECs) and the possible mechanisms. Cultured BMECs were treated with $\mathrm{H}_{2} \mathrm{O}_{2}$, STL, or nicotinamide (NAM, a SIRT1 inhibitor). Then, 3-(4,5-dimethylthiazol-2-yl)-2,5-diphenyl-2H-tetrazolium bromide (MTT) assay was employed to detect cell proliferation and senescence-associated beta-galactosidase (SA- $\beta$-gal) was used to examine cell senescence. Cell nuclei were observed by 4',6-diamidino-2-phenylindole. Additionally, changes in reactive oxygen species (ROS), superoxide dismutase (SOD), and glutathione (GSH) levels were measured. Expression of SIRT1, p21, and PGC-1 $\alpha$ was determined by western blot. Cell proliferation significantly increased with STL treatment in a dose-dependent manner. $\mathrm{H}_{2} \mathrm{O}_{2}$ treatment could intensify cell senescence and nuclei splitting or pyknosis. With STL treatment, the reduced ROS level was accompanied by increased SOD and GSH activity. Further assays showed upregulation of SIRT1 and PGC- $1 \alpha$ and downregulation of p 21 after STL treatment. The results revealed that STL could protect BMECs against oxidative stress injury at least partially through the SIRT1 pathway.
\end{abstract}

\section{Introduction}

During normal physiological conditions, reactive oxygen species (ROS) are produced at low levels and are scavenged by endogenous antioxidant systems that include superoxide dismutase (SOD), glutathione peroxidase, catalase, and small-molecule substances such as vitamins C and E [1]. But abundant accumulation of ROS may partially account for the pathogenesis of vascular diseases such as atherosclerosis, hypertension, stroke, neurodegenerative diseases, diabetes, and aging [2,3]. It is strongly associated with endothelial dysfunction development such as endothelial injury, mitochondrial damage, inflammation, autophagy, apoptosis, and aging [4-7]. Also, ROS play an important role in mediating apoptotic death and survival in endothelial cells [8]. As a member of the brain microvascular wall, brain microvascular endothelial cells (BMECs) are the most important part of the blood-brain barrier [9] and participate in regulating vascular tone, blood fluidity and adhesiveness, and normal blood circulation [10]. Moreover, silent information regulator 1 (SIRT1) is a member of the sirtuin family of proteins, which are homologs of the Sir2 gene in Saccharomyces cerevisiae [11], which is highly expressed in the vasculature [12]. SIRT1 is an NAD-dependent deacetylase and modulates many biological processes, including oxidative stress, energy metabolism, cell differentiation, and genomic stability [13]. It has been 
reported that SIRT1 offered significant protection for cell survival in a number of disorders during oxidative stress $[14,15]$.

Recent studies have shown that traditional Chinese herbs or formulae, such as puerarin [16], curcumin [17], and Buyang Huanwu Decoction [18], were popularly used to attenuate oxidative stress injury and protect endothelial cells from $\mathrm{H}_{2} \mathrm{O}_{2}$-induced apoptosis by inhibiting oxidative stress damage or ROS-mediated mitochondrial dysfunction. In traditional Chinese medicine, $q i$ is an energy that can invigorate the body and enhance blood circulation and meridian circulation [19-21]. These herbs or formulae have the functions of promoting $q i$ flow and soothing liver and activating blood circulation according to the theory of traditional Chinese medicine.

Shuan-Tong-Ling (STL) is a new fermented Chinese formula, which is an experiential formula by Dr. Mei for treating vascular encephalopathy, which was adapted from a classical prescription, Sanpian Decoction. It is a famous traditional Chinese formula which was invented by Dr. Shiduo Chen in the Ming Dynasty for treating stroke, vascular migraine, and so forth one hundred years ago [22, 23]. STL was comprised of 14 herbs, such as Radix Puerariae (Gegen), Salvia miltiorrhiza (Danshen), Radix Paeoniae Alba (Baishao), and Astragalus (Huangqi), which was fermented with Lactobacillus, Bacillus aceticus, and Saccharomyces. Although STL has been used to treat stroke, migraine, vascular dementia, and so on in clinic, however, the mechanism behind the beneficial effects of STL has not been explained clearly.

This study focused on determining the efficacy of STL on the $\mathrm{H}_{2} \mathrm{O}_{2}$-induced injury in BMECs and exploring the possible mechanisms.

\section{Materials and Methods}

2.1. Cell Culture. Rat brain microvascular endothelial cells (BMECs), brought from Shanghai Sxbio Biotechnology Co., Ltd., of Shanghai, were cultured in Dulbecco's modified Eagle's medium (DMEM) (Gibco, Grand Island, NY, USA) containing $15 \%$ heat-inactivated $\left(56^{\circ} \mathrm{C}, 0.5 \mathrm{~h}\right)$ fetal bovine serum (Gibco, Grand Island, NY, USA), $100 \mathrm{U}$ penicillin, and $100 \mu \mathrm{g} / \mathrm{mL}$ streptomycin (Gibco, Grand Island, NY, USA) at $37^{\circ} \mathrm{C}$ in a $5 \% \mathrm{CO}_{2}$ humidified atmosphere. Cells were seeded in culture flasks or dishes (Corning, NY, USA), grown to 75$80 \%$ confluency, and treated with $\mathrm{H}_{2} \mathrm{O}_{2}$ or pretreated with STL or SIRT1 inhibitor before $\mathrm{H}_{2} \mathrm{O}_{2}$ treatment, as stated in the following sections.

2.2. Preparation of STL Sample and Fermented STL. Fourteen herbs composing STL were obtained from Yichang Hospital of Traditional Chinese Medicine, Hubei province, China, which were classified into 3 groups based on the theory of Chinese medicine. Radix Puerariae (Gegen), Salvia miltiorrhiza (Danshen), Radix Curcuma (Jianghuang), hawthorn (Shanzha), Salvia chinensis (Shijianchuan), and Sinapis alba (Baijiezi) were used for promoting $q i$ and enhance blood circulation. Astragalus (Huangqi), Panax japonicas (Zhujieshen), and Atractylodes macrocephala Koidz (Baizhu) were used for invigorating $q i$ and enriching blood. Radix Paeoniae Alba (Baishao), Bupleurum (Chaihu), Chrysanthemum (Juhua), Rhizoma Cyperi (Xiangfu), and gastrodin (Tianma) were used for modulating abnormal liquid metabolism and soothing the liver. Chopped herbs mixture at a certain weight percentage was submerged in water for $30 \mathrm{~min}$ and heated for $1 \mathrm{~h}$ at $100^{\circ} \mathrm{C}$ in marmite. Then, the herb decoction was fermented with Lactobacillus, Bacillus aceticus, and Saccharomyces for 10 days at $37^{\circ} \mathrm{C}$. After sterilizing and pasteurization, final fermented liquid STL was canned and stored at $4^{\circ} \mathrm{C}$ (Figure 1).

2.3. Qualitative Analysis of Active Ingredients. Based on the theories of traditional Chinese medicine, an herbal formulation contains more than one Chinese herb. According to the literature, the effective components of STL were astragaloside IV, paeoniflorin, puerarin, curcumin, tanshinone IIA, and Chikusetsu V. These active ingredients were qualitatively controlled by high-performance liquid chromatography (HPLC) in our study. Standard chemicals including astragaloside, paeoniflorin, puerarin, curcumin, tanshinone IIA, and Chikusetsu V were purchased from Chengdu Mann Stewart Biological Technology Co. Ltd. (Chengdu, China). Briefly, HPLC profiling was performed using an Agilent 1260 series equipped with a quaternary solvent delivery system, autosampler, and a photodiode array (PDA) detector (Waters Breeze, USA). Separation was performed on an Agilent Zorbax SB-C18 column $(150 \mathrm{~mm} \times 4.6 \mathrm{~mm}, 5 \mu \mathrm{m}$; temperature: $30^{\circ} \mathrm{C}$, flow rate: $1 \mathrm{~mL} / \mathrm{min}$; injection volume: $10 \mu \mathrm{L}$ ). The linear assessment of paeoniflorin and puerarin and curcumin gradient elution with deionized water (A) and methanol (B) was performed as follows: $0-15$ min with $25-$ $75 \%$ of $\mathrm{B} ; 15-20$ min with $75 \%$ of $\mathrm{B} ; 20-23$ min with $75-80 \%$ of B; 23-26 min with $80-25 \%$ of B. The linear assessment of Chikusetsu $\mathrm{V}$ gradient elution with $0.1 \%$ phosphoric acid in water (A) and methanol (B) was performed as follows: 010 min with $22.5 \%$ of $\mathrm{B} ; 10-15$ min with $22.5-40 \%$ of $\mathrm{B}$; $15-$ 20 min with $40-60 \%$ of $B ; 20-25$ min with $60 \%$ of $B$; $25-$ 30 min with $60-40 \%$ of $\mathrm{B} ; 30-35$ min with $40-22.5 \%$ of $\mathrm{B}$. The linear assessment of tanshinone IIA gradient elution with deionized water (A) and methanol (B) was performed as follows: $0-20 \mathrm{~min}$ with $85 \%$ of $\mathrm{B} ; 20-30 \mathrm{~min}$ with $85-100 \%$ of $\mathrm{B} ; 30-40 \mathrm{~min}$ with $100-85 \%$ of $\mathrm{B}$. The mobile phase of astragaloside IV was used as methanol/water (35/65), with 5 -minute reequilibration of the gradient elution. The detection wavelength of astragaloside IV, paeoniflorin, puerarin, curcumin, and Chikusetsu V was $203 \mathrm{~nm}, 230 \mathrm{~nm}, 250 \mathrm{~nm}$, $430 \mathrm{~nm}, 230 \mathrm{~nm}$, and $270 \mathrm{~nm}$, respectively.

2.4. Oxidative Stress Model and Treatment of the STL and Inhibitor of SIRT1. BMECs were randomly divided into four groups: (1) the control group (BMECs were cultured in normal conditions as described above); (2) the $\mathrm{H}_{2} \mathrm{O}_{2}$ group (BMECs were treated with $\mathrm{H}_{2} \mathrm{O}_{2}$ (Sinopharm Chemical Reagent Co., Ltd., Shanghai, China) at different concentrations of $0,50,100,200,400,600$, and $800 \mu \mathrm{mol} / \mathrm{L}$ ); (3) the STL group (which includes four different subgroups, in which BMECs were pretreated with final concentrations of $0,0.0125,0.025,0.05,0.1,0.2$, and $0.4 \mathrm{~g} / \mathrm{L}, 12 \mathrm{~h}$ before adding 


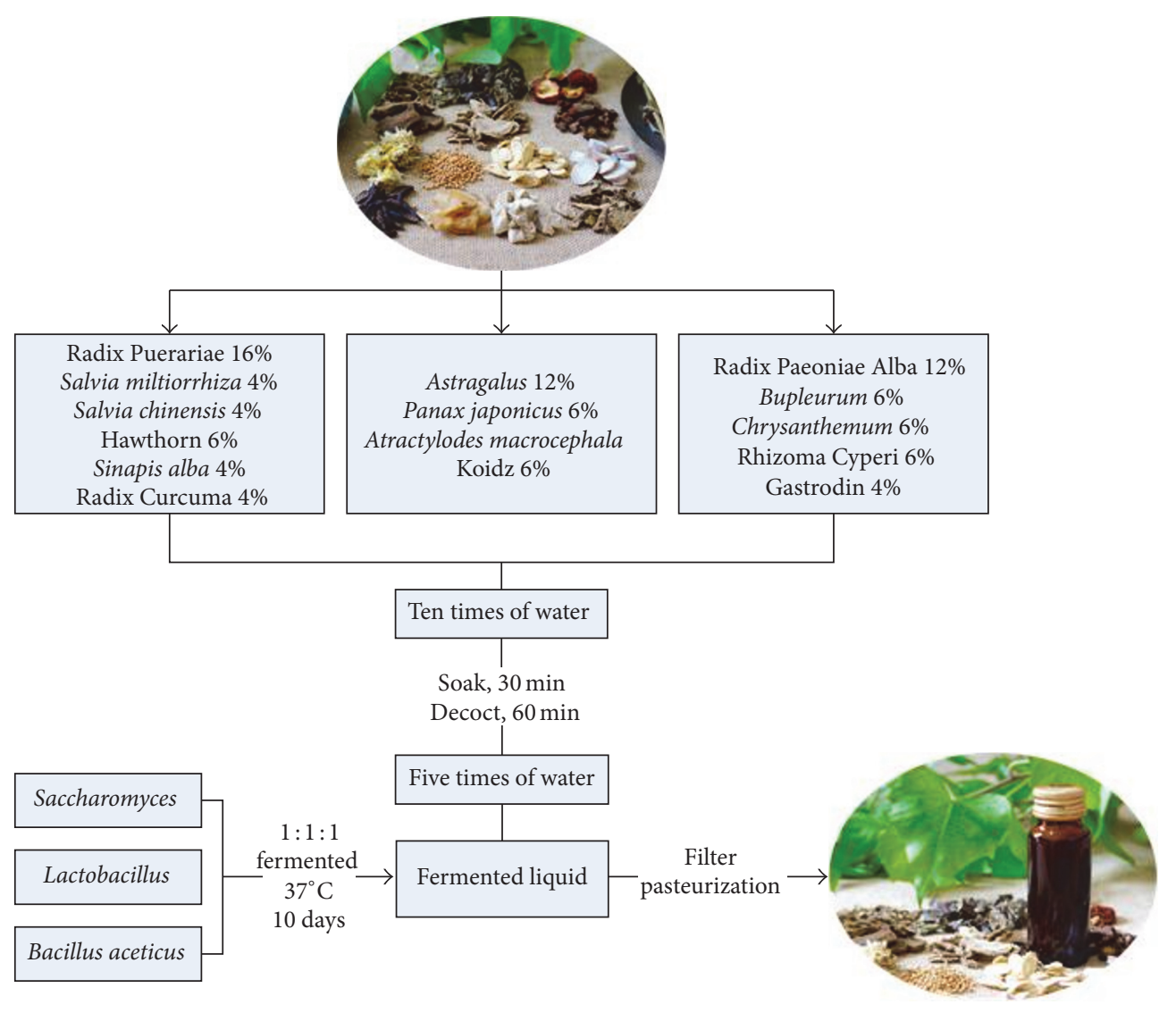

FIGURE 1: Flow chart of the manufacturing process of STL.

$\mathrm{H}_{2} \mathrm{O}_{2}$ to a final concentration of $400 \mu \mathrm{mol} / \mathrm{L}$ ); (4) the SIRT1 inhibitor nicotinamide (NAM) (Beyotime, Haimen, China) group (NAM group) (BMECs were pretreated with NAM at final concentrations of $50 \mu \mathrm{mol} / \mathrm{L}, 12 \mathrm{~h}$ before adding $\mathrm{H}_{2} \mathrm{O}_{2}$ to a final concentration of $400 \mu \mathrm{mol} / \mathrm{L}$ ).

2.5. Measurement of Cell Proliferation by MTT Assay. Cells were cultured in 96-well plates. MTT (Sigma-Aldrich, St. Louis, MO, USA) was dissolved in phosphate-buffered PBS at a concentration of $5 \mathrm{mg} / \mathrm{mL}$. Then, the solution was filtered through a $0.2 \mu \mathrm{M}$ filter and stored at $2-8^{\circ} \mathrm{C}$. At $0.5 \mathrm{~h}$ before the end of the equilibration, $20 \mu \mathrm{L}$ of MTT solution was added to each well; and cultures were incubated at $37^{\circ} \mathrm{C}$ for $4-5 \mathrm{~h}$. The media were removed with a pipette, $150 \mu \mathrm{L}$ of DMSO was added to each well to dissolve the crystals, and the cell plates were covered with tinfoil, agitated on a shaker for $15 \mathrm{~min}$, and finally subjected to a plate reader to read absorbance at $570 \mathrm{~nm}$.

2.6. $\beta$-Galactosidase Staining. The activity of senescenceassociated $\beta$-galactosidase (SA- $\beta$-gal), a marker of cellular senescence, was determined by using the Cellular Senescence Assay Kit (Beyotime, Haimen, China) according to the manufacturer's instructions. Cells were fixed and incubated with a solution containing the $\beta$-gal substrate, abbreviated $\mathrm{X}$ gal (5-bromo-4-chloro-3-indoxyl-b-galactoside). $48 \mathrm{~h}$ after transfection as indicated above, cells were washed three times with PBS, fixed with $1 x$ fixing solution, and incubated at room temperature for $10 \mathrm{~min}$. After removing the fixing solution, cells were washed three times again with PBS and incubated overnight with freshly prepared 1x SA- $\beta$-gal detection solution at $37^{\circ} \mathrm{C}$, without $\mathrm{CO}_{2}$, and protected from light. The percentages of blue-stained senescent cells (SA- $\beta$ gal-positive) were determined by counting 150 to 200 cells in five microscopic fields.

2.7. Immunostaining. BMECs were seeded on cover glass at a density of $1 \times 10^{4}$ cells/well in DMEM supplemented with $10 \%$ FBS. One day after plating, cells were pretreated with STL $(0.05,0.1$, and $0.2 \mathrm{~g} / \mathrm{L})$ for $12 \mathrm{~h}$. The cells were then exposed to $\mathrm{H}_{2} \mathrm{O}_{2}(400 \mu \mathrm{mol} / \mathrm{L})$ for $24 \mathrm{~h}$ before incubating in fixed $4 \%$ paraformaldehyde solution. Then, cells were washed three times again with PBS and were stained with 2-(4-amidinophenyl)-6-indolecarbamidine dihydrochloride (DAPI) at $0.5 \mu \mathrm{M}$ for $30 \mathrm{~min}$ in room temperature. Then, cells were washed three times again with PBS. Then, cells were seeded onto glass cover slides, which were subsequently coated with glycerin. Cells were observed with $400 x$ magnification under microscope (Leica, Germany) in five microscopic fields.

2.8. Measurement of Reactive ROS. Measurement of intracellular ROS was based on ROS-mediated conversion of nonfluorescent 2,7-DCFH-DA into fluorescent DCFH. Briefly, 
BMECs were seeded on cover glass at a density of $1 \times$ $10^{4}$ cells/well in DMEM supplemented with $10 \%$ FBS. One day after plating, cells were pretreated with STL $(0.05,0.1$, and $0.2 \mathrm{~g} / \mathrm{L}$ ) for $12 \mathrm{~h}$. The cells were then exposed to $\mathrm{H}_{2} \mathrm{O}_{2}$ $(400 \mu \mathrm{mol} / \mathrm{L})$ for $24 \mathrm{~h}$ before incubating in 2,7-DCFH-DA (Beyotime, Haimen, China) at $10 \mu \mathrm{M}$ in PBS for $30 \mathrm{~min}$. Cells were washed three times with PBS and then the DCFH fluorescence from each well was excited at $488 \mathrm{~nm}$ and the emission was measured at $525 \mathrm{~nm}$ by fluorescence microscopy (Leica TCS SP5, Wetzlar, Germany). The cells were collected and observed with 400x magnification in five microscopic fields. The fluorescence of DCFH was analyzed using Image Pro plus 6.0 software (Media Cybernetics, USA).

2.9. Measurement of Reactive SOD and GSH. Briefly, after incubating as described above, cells were lysed and centrifuged at $12,000 \times \mathrm{g}$ for $10 \mathrm{~min}$ at $4^{\circ} \mathrm{C}$, to collect the supernatant. A commercial superoxide dismutase assay kit (Research \& Diagnostic Systems, Inc., USA) and a glutathione assay kit (Research \& Diagnostic Systems, Inc., USA) were used in quantification of SOD and GSH activity. The SOD and GSH levels in the supernatant were measured according to the kit protocol and analyzed on a spectrophotometer. The absorbance was read at $550 \mathrm{~nm}$ (SOD) and $405 \mathrm{~nm}$ (GSH).

2.10. Western Blot Analysis. BMECs were seeded into 25 $\times 25 \mathrm{~cm}^{2}$ flasks (Corning, NY, USA) and were cultured in DMEM supplemented with 10\% FBS. Then, different treatments were administrated to the cells as described above. The cells were collected with a lysis buffer (Beyotime, Shanghai, China). The cleared total cell lysate was denatured via boiling and resolved via $10 \%$ sodium dodecyl sulfatepolyacrylamide gel electrophoresis. After electrophoretic separation, the proteins were transferred to a polyvinylidene fluoride membrane (Millipore, Bedford, MA, USA). The membrane was blocked with $5 \%$ skim milk for $1 \mathrm{~h}$ at room temperature and probed overnight with anti-SIRT1 (Santa Cruz, CA, USA; $1: 1000$ ), anti-PGC-1 $\alpha$ (Thermo Fisher Scientific, USA; 1: 500), anti-p21 (Cell Signaling Technology, USA; $1: 1000$ ), and anti- $\beta$-actin (Boster, Wuhan, China; $1: 2000$ ) at $4^{\circ} \mathrm{C}$. After three washes, the blots were incubated with a goat anti-rabbit or rabbit anti-mouse peroxidase-conjugated secondary antibody (Boster, Wuhan, China; $1: 3000$ ) for $1 \mathrm{~h}$ at room temperature. The blots were displayed in Immobilon Western Chemiluminescent HRP Substrate (Boster, Wuhan, China). The protein expression levels were compared to those of $\beta$-actin using Quantity One software (ImageJ software, Materialise NV, Leuven, Belgium).

2.11. Statistical Analyses. Data are presented as mean \pm standard deviation (SD). Analysis of variance was used for multiple comparisons of groups. All the analysis was carried out with GraphPad Prism 6.0 (GraphPad Software, San Diego, CA, USA). Least significant difference (LSD) analysis was used to compare the means between each of the two groups. A $P$ value $<0.05$ was considered statistically significant.

\section{Results}

3.1. Qualitative Analysis of STL Components. We used HPLC to identify the active ingredients that STL extracts contain. As shown in Figure 2, STL contained astragaloside IV, paeoniflorin, puerarin, curcumin, and Chikusetsu V, but not tanshinone IIA. The summit retention time of astragaloside IV, paeoniflorin, puerarin, curcumin, and Chikusetsu V was approximately $5.8 \mathrm{~min}, 7.3 \mathrm{~min}, 6.1 \mathrm{~min}, 18.6 \mathrm{~min}$, and $18.7 \mathrm{~min}$, respectively.

3.2. Effects of $\mathrm{H}_{2} \mathrm{O}_{2}$ and STL on BMECs Proliferation. As shown in Figure 3(a), cell proliferation significantly decreased with $\mathrm{H}_{2} \mathrm{O}_{2}$ treatment in a dose-dependent manner when compared with control group $(P<0.01)$. Considering the above cell proliferation, $400 \mu \mathrm{mol} / \mathrm{L}$ of $\mathrm{H}_{2} \mathrm{O}_{2}$ was chosen to induce injury in BMECs. As shown in Figure 3(b), treatment with STL at $0.0125 \mathrm{~g} / \mathrm{L}$ for $12 \mathrm{~h}$ did not affect BMECs proliferation. However, treatment with $0.025,0.05$, and $0.1 \mathrm{~g} / \mathrm{L}$ STL statistically significantly decreased cell proliferation $(P<$ 0.01 ) when compared with control group. As shown in Figure 3(c), $400 \mu \mathrm{mol} / \mathrm{L} \mathrm{H}_{2} \mathrm{O}_{2}$ effectively increased the cells $(P<$ 0.01 ) when compared with control group, while pretreatment with STL at $0.025,0.5$, and $0.1 \mathrm{~g} / \mathrm{L}$ could significantly attenuate the $\mathrm{H}_{2} \mathrm{O}_{2}$-induced BMECs injury $(P<0.01)$ when compared with $\mathrm{H}_{2} \mathrm{O}_{2}(400 \mu \mathrm{mol} / \mathrm{L})$ group.

3.3. Effect of STL on $\mathrm{H}_{2} \mathrm{O}_{2}$-Induced Injury in BMECs Nuclei. To evaluate the effect of STL on $\mathrm{H}_{2} \mathrm{O}_{2}$-induced injury in BMECs nuclei, cells were stained with DAPI. Different forms of cell nuclear alterations including karyorrhexis, karyopyknosis, and karyolysis were observed after DAPI staining (blue). Considering the cell proliferation, $400 \mu \mathrm{mol} / \mathrm{L}$ of $\mathrm{H}_{2} \mathrm{O}_{2}$ was chosen to induce injury in BMECs. As shown in Figures $4(\mathrm{a})$ and $4(\mathrm{~b})$, exposure to $\mathrm{H}_{2} \mathrm{O}_{2}$ increased injury when compared with control group. As shown in Figures 4(c), 4(d), and 4(e), treatment with STL significantly reduced apoptotic cells in a dose-dependent manner when compared with $\mathrm{H}_{2} \mathrm{O}_{2}$ group. This suggests that STL may block BMECs nuclei injury.

3.4. Effect of STL on Senescence in $\mathrm{H}_{2} \mathrm{O}_{2}$-Induced Injury in BMECs. To evaluate the effect of STL on $\mathrm{H}_{2} \mathrm{O}_{2}$-induced senescence, cells were stained with SA- $\beta$-gal. SA- $\beta$-galpositive cells (blue) were considered as senescence cells. Considering the cell proliferation, $400 \mu \mathrm{mol} / \mathrm{L}$ of $\mathrm{H}_{2} \mathrm{O}_{2}$ was chosen to induce injury in BMECs. As shown in Figures 5(a) and 5(b), exposure to $\mathrm{H}_{2} \mathrm{O}_{2}$ increased senescence when compared with control group. As shown in Figures 5(c), 5(d), and 5(e), treatment with STL significantly reduced senescence cells in a dose-dependent manner when compared with $\mathrm{H}_{2} \mathrm{O}_{2}$ group. This suggests that STL may block senescence pathway.

3.5. Effect of STL on ROS Level in $\mathrm{H}_{2} \mathrm{O}_{2}$-Induced Injury in $B M E C s$. To measure intracellular ROS levels using fluorescence microscopy with DCFH-DA, DCFH-DA is cleaved intracellularly by esterase and subsequently oxidized to DCFH by ROS. Green fluorescence produced by DCFH 


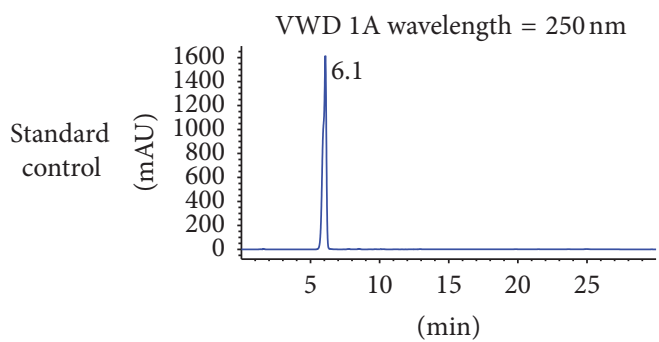

VWD 1A wavelength $=250 \mathrm{~nm}$
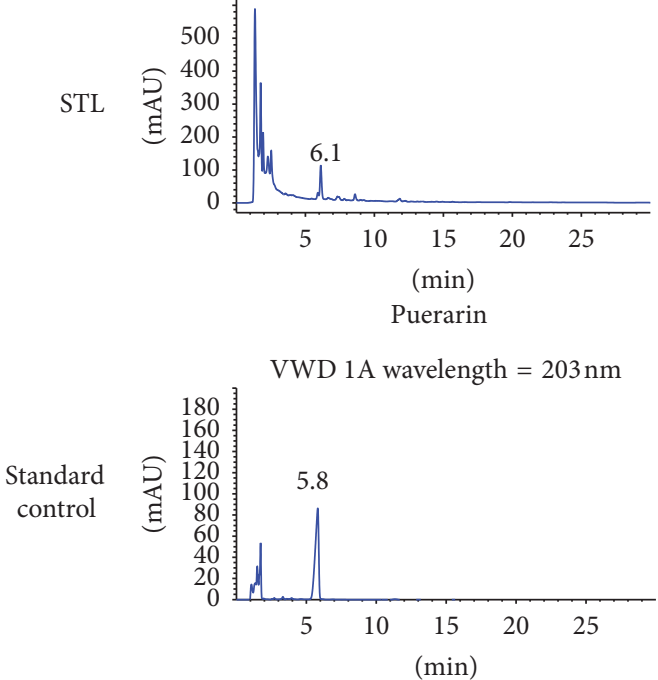

VWD 1A wavelength $=203 \mathrm{~nm}$

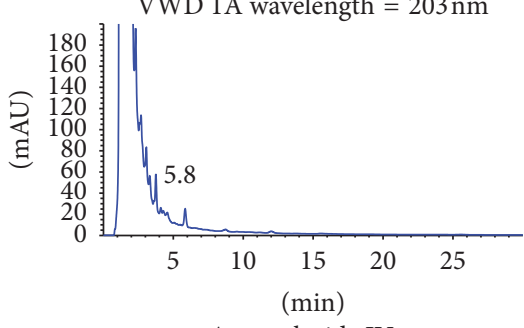

Astragaloside IV

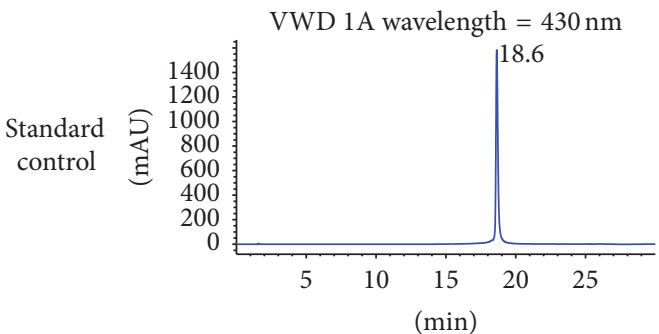

VWD 1A wavelength $=430 \mathrm{~nm}$

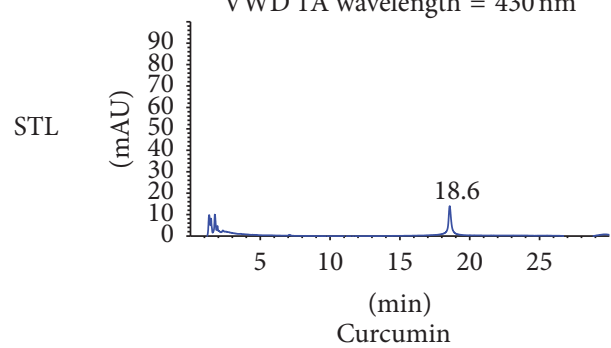

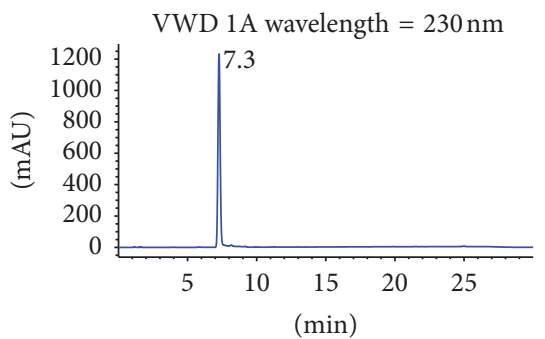

VWD 1A wavelength $=250 \mathrm{~nm}$

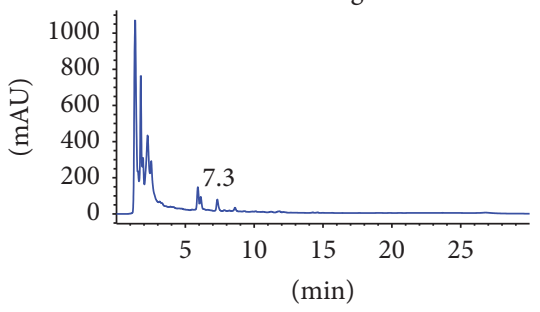

Paeoniflorin
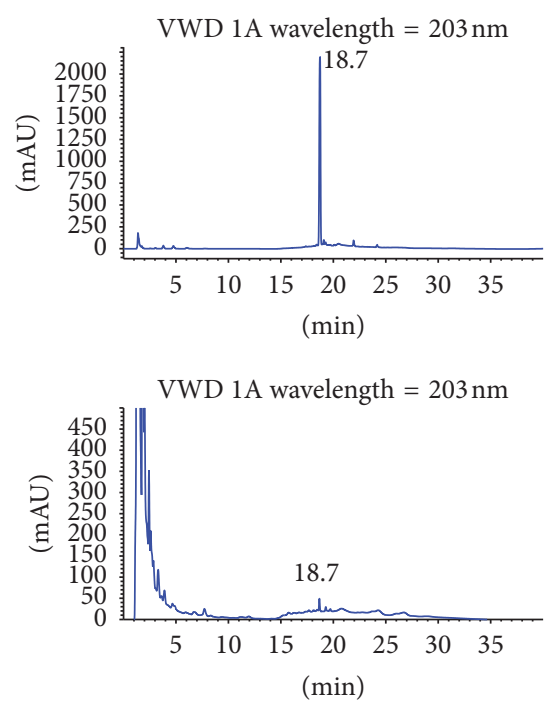

Chikusetsu saponin V

VWD 1A wavelength $=270 \mathrm{~nm}$
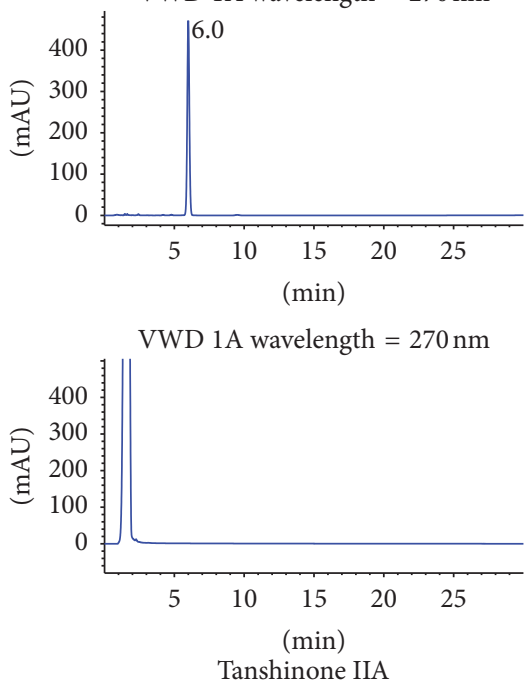

FIGURE 2: HPLC chromatograms of active ingredients in STL and standard controls. STL contained puerarin, paeoniflorin, astragaloside IV, Chikusetsu V, and curcumin, but not tanshinone IIA. The summit retention time of puerarin, paeoniflorin, astragaloside IV, Chikusetsu V, and curcumin was approximately $6.1 \mathrm{~min}, 7.3 \mathrm{~min}, 5.8 \mathrm{~min}, 18.7 \mathrm{~min}$, and $18.6 \mathrm{~min}$, respectively. 


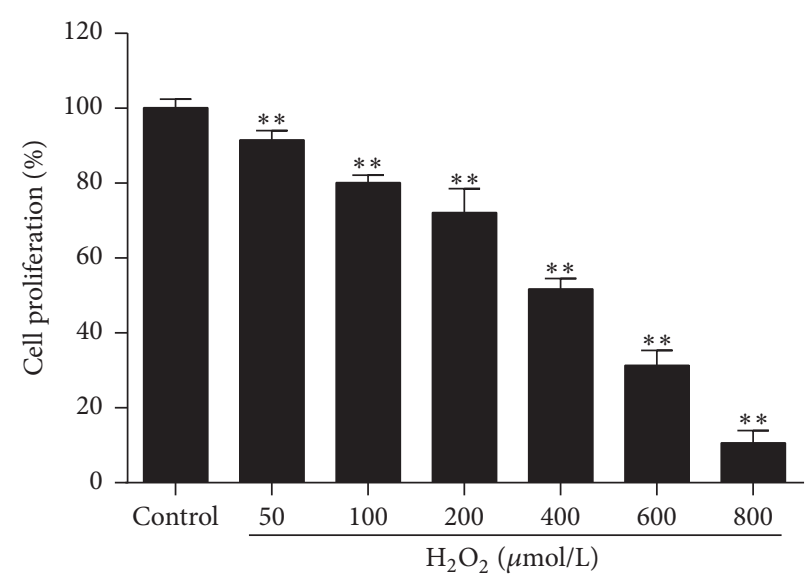

(a)

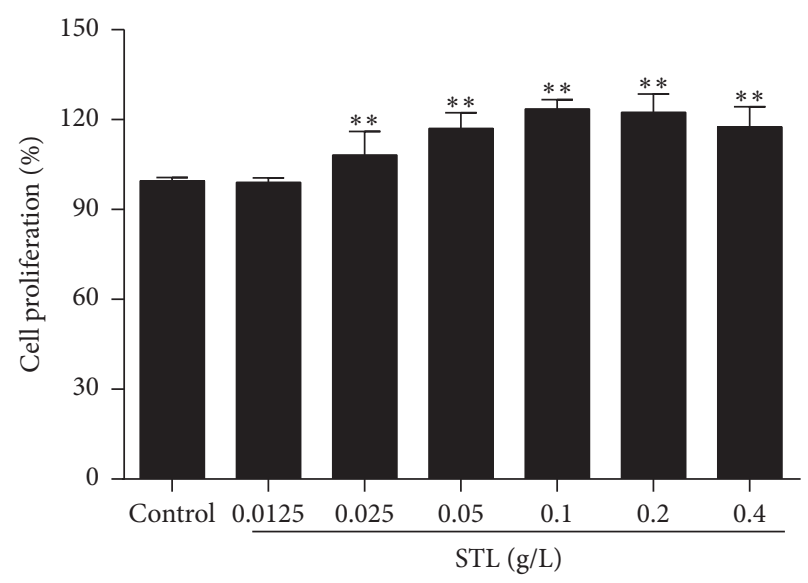

(b)

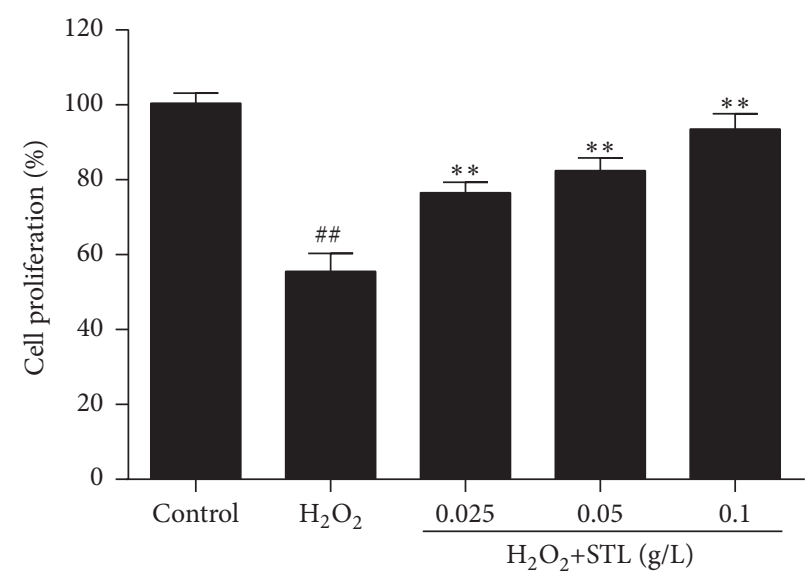

(c)

Figure 3: (a) Effects of $\mathrm{H}_{2} \mathrm{O}_{2}$ on BMECs proliferation. ${ }^{* *} P<0.01$ compared to control group. (b) Effects of STL on BMECs proliferation. ${ }^{* *} P<0.01$ compared to control group. (c) Effects of $\mathrm{H}_{2} \mathrm{O}_{2}$ and STL on BMECs proliferation. ${ }^{\# \#} P<0.01$ compared to control group. ${ }^{* *} P<0.01$ compared to $\mathrm{H}_{2} \mathrm{O}_{2}$ group.

indicates abnormally high ROS levels. Considering the cell proliferation, $400 \mu \mathrm{mol} / \mathrm{L}$ of $\mathrm{H}_{2} \mathrm{O}_{2}$ was chosen to induce injury in BMECs. As shown in Figures 6(a), 6(b), and 6(c), exposure to $\mathrm{H}_{2} \mathrm{O}_{2}$ decreased $(P<0.01)$ and STL group increased when compared with control group. As shown in Figures 6(d) and 6(e), treatment with STL increased ROS levels when compared with $\mathrm{H}_{2} \mathrm{O}_{2}$ group. This suggests that STL inhibits $\mathrm{H}_{2} \mathrm{O}_{2}$-induced ROS production.

3.6. Effect of STL on SOD and GSH Levels in $\mathrm{H}_{2} \mathrm{O}_{2}$-Induced Injury in BMECs. SOD and GSH levels activity indirectly reflects the ability to eliminate ROS. To determine whether STL affects ROS-induced cell damage, we examined intracellular SOD and GSH levels. As shown in Figure 7, exposure to $\mathrm{H}_{2} \mathrm{O}_{2}$ decreased SOD and GSH levels $(P<0.01)$ when compared with control group and treatment with STL increased SOD and GSH levels $(P<0.01)$ when compared with $\mathrm{H}_{2} \mathrm{O}_{2}$ group. These findings suggest that STL prompts $\mathrm{H}_{2} \mathrm{O}_{2}$ induced SOD and GSH levels. Moreover, NAM treatment significantly inhibited the effects of STL $(0.1 \mathrm{~g} / \mathrm{L})$ on the protein expression of SOD and GSH $(P<0.01)$ when compared with STL and $\mathrm{H}_{2} \mathrm{O}_{2}$ group.
3.7. Effect of STL on SIRT1, PGC-1 $\alpha$, and p21 Protein Expression in $\mathrm{H}_{2} \mathrm{O}_{2}$-Induced Injury in BMECs. As shown in Figure 8, levels of SIRT1 protein expression were detected in $\mathrm{H}_{2} \mathrm{O}_{2}$ induced injury by western blotting. SIRT1 protein expression of $\mathrm{H}_{2} \mathrm{O}_{2}$-induced injury BMECs group significantly declined $(P<0.01)$ when compared to the control group. Treatment with STL increased SIRT1 protein expression $(P<0.01)$ when compared to the $\mathrm{H}_{2} \mathrm{O}_{2}$ group. Moreover, NAM treatment significantly suppressed the effect of STL $(0.1 \mathrm{~g} / \mathrm{L})$ on the protein expression of SIRT1 $(P<0.05)$. And levels of PGC- $1 \alpha$ protein expression were detected in $\mathrm{H}_{2} \mathrm{O}_{2}$-induced injury by western blotting. PGC- $1 \alpha$ protein expression of $\mathrm{H}_{2} \mathrm{O}_{2}$-induced injury BMECs group was significantly downregulated $(P<0.01)$ when compared to the control group. Treatment with STL increased PGC- $1 \alpha$ protein expression $(P<0.01)$ when compared to the $\mathrm{H}_{2} \mathrm{O}_{2}$ group. Moreover, NAM treatment significantly suppressed the effect of STL $(0.1 \mathrm{~g} / \mathrm{L})$ on the protein expression of PGC- $1 \alpha(P<0.05)$. The levels of $\mathrm{p} 21$ protein expression were detected in $\mathrm{H}_{2} \mathrm{O}_{2}$-induced injury by western blotting. The p21 protein expression in $\mathrm{H}_{2} \mathrm{O}_{2}$ induced injury BMECs group was significantly upregulated $(P<0.01)$ when compared to the control group. Treatment 


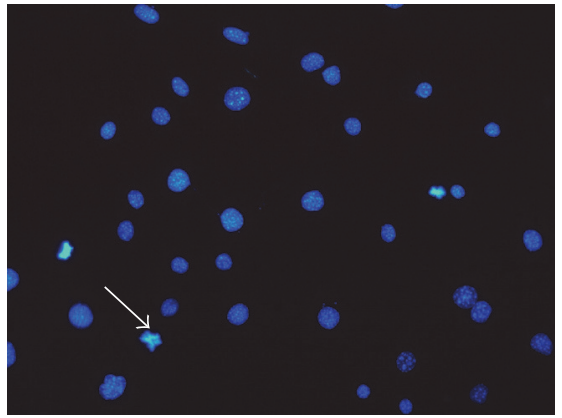

(a)

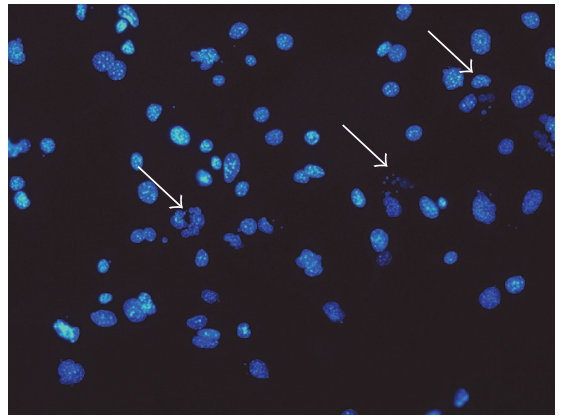

(b)

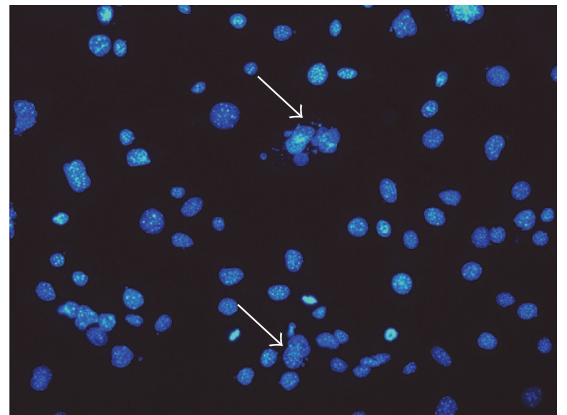

(c)

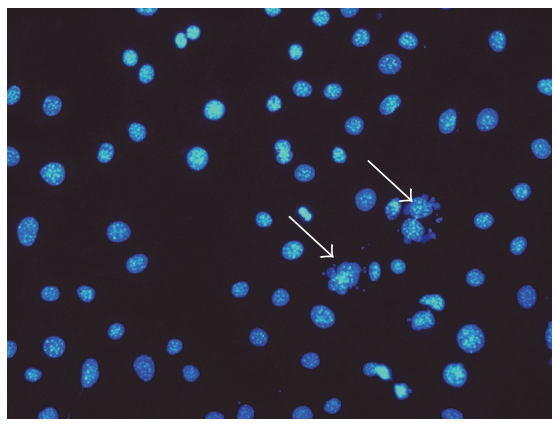

(d)

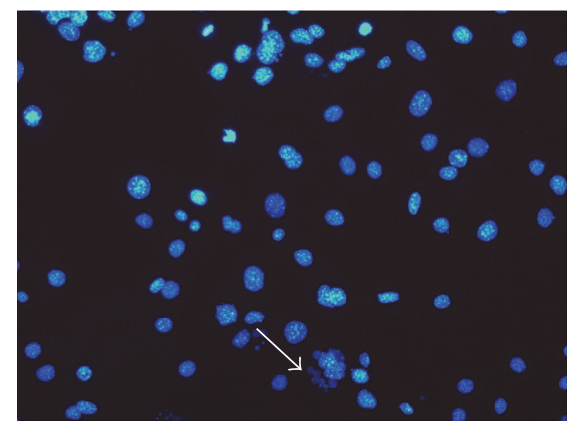

(e)

Figure 4: Effect of STL on $\mathrm{H}_{2} \mathrm{O}_{2}$-induced injury in BMECs nuclei. (a) Control group; (b) $\mathrm{H}_{2} \mathrm{O}_{2}$ group; (c) $\mathrm{H}_{2} \mathrm{O}_{2}+\mathrm{STL}$ (0.025 g/L); (d) $\mathrm{H}_{2} \mathrm{O}_{2}+\mathrm{STL}(0.05 \mathrm{~g} / \mathrm{L}) ;(\mathrm{e}) \mathrm{H}_{2} \mathrm{O}_{2}+\mathrm{STL}(0.1 \mathrm{~g} / \mathrm{L})$.

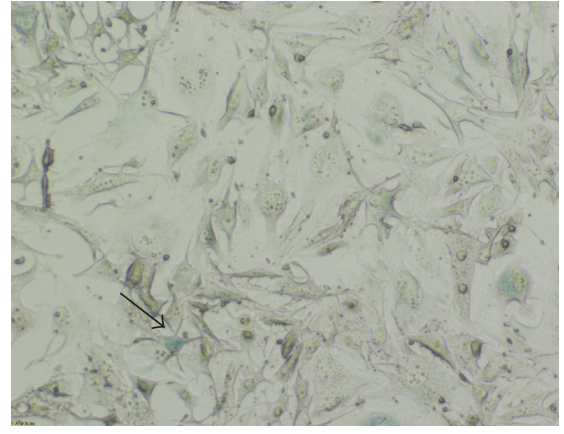

(a)

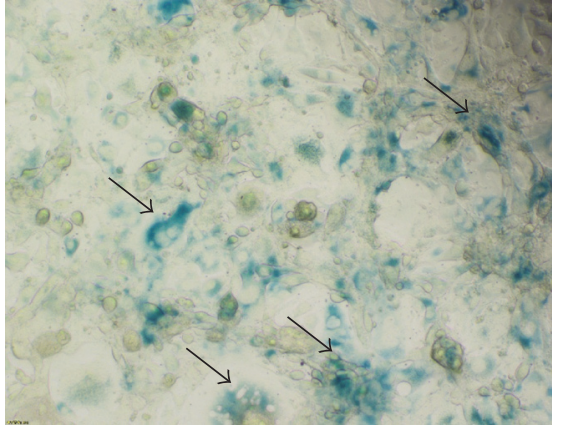

(b)

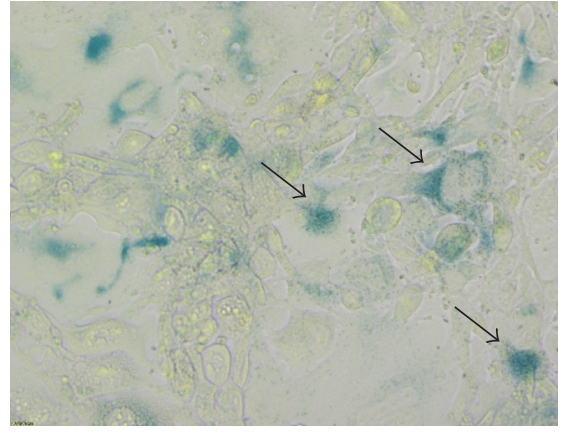

(c)

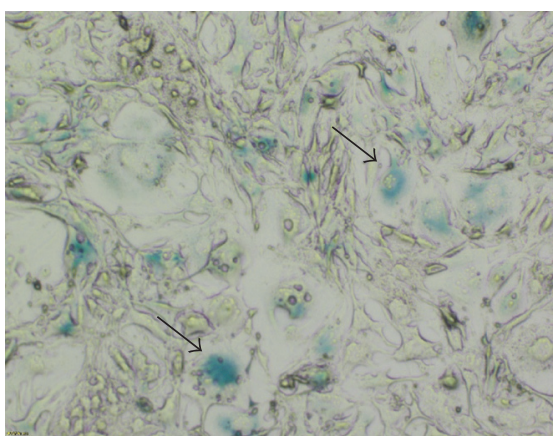

(d)

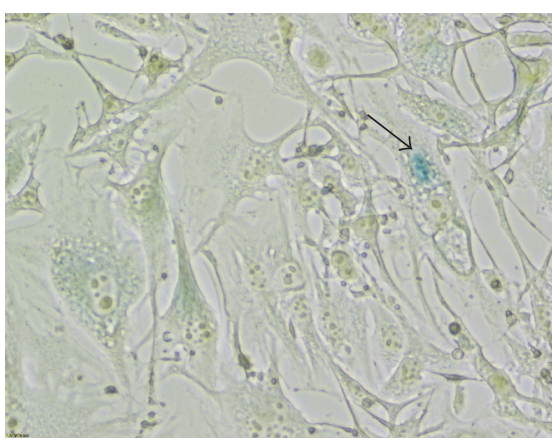

(e)

FIGURE 5: Effect of STL on senescence in $\mathrm{H}_{2} \mathrm{O}_{2}$-induced injury in BMECs. (a) Control group; (b) $\mathrm{H}_{2} \mathrm{O}_{2}$ group; (c) $\mathrm{H}_{2} \mathrm{O}_{2}+\mathrm{STL}$ (0.025 g/L); (d) $\mathrm{H}_{2} \mathrm{O}_{2}+\mathrm{STL}(0.05 \mathrm{~g} / \mathrm{L}) ;(\mathrm{e}) \mathrm{H}_{2} \mathrm{O}_{2}+\mathrm{STL}(0.1 \mathrm{~g} / \mathrm{L})$. 


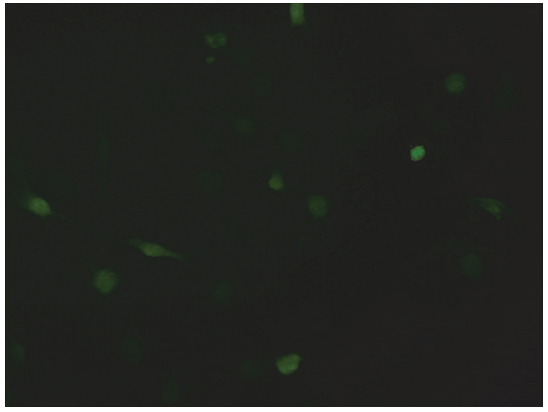

(a)

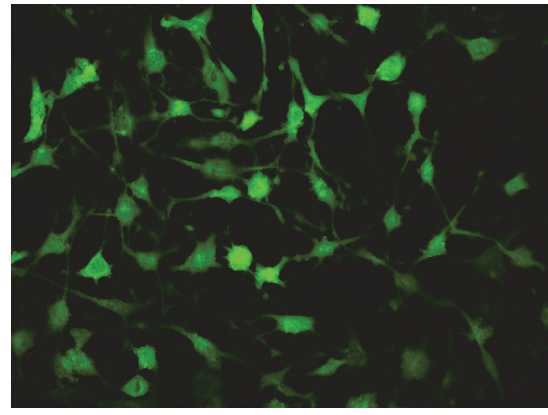

(b)

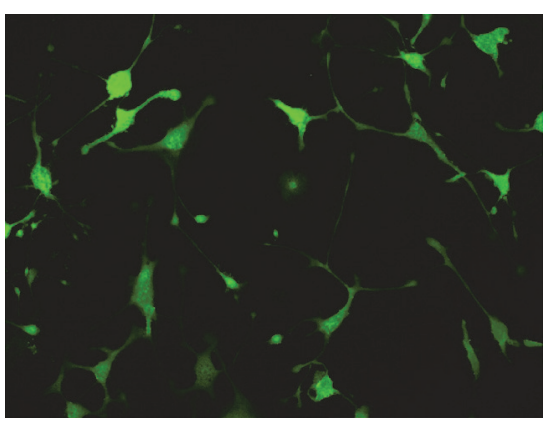

(c)

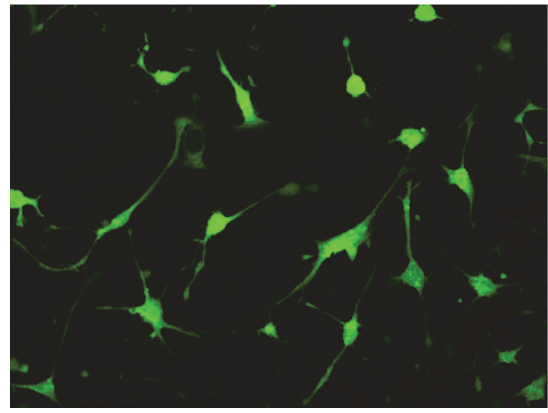

(d)

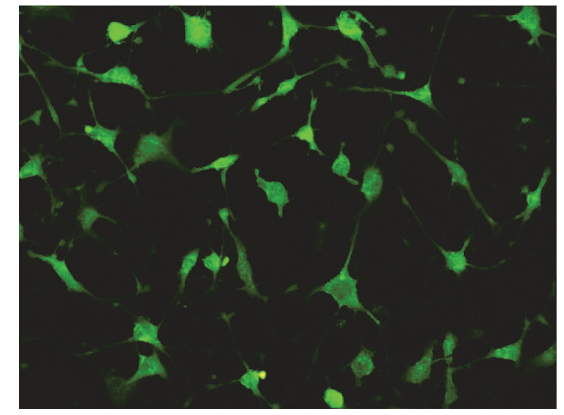

(e)

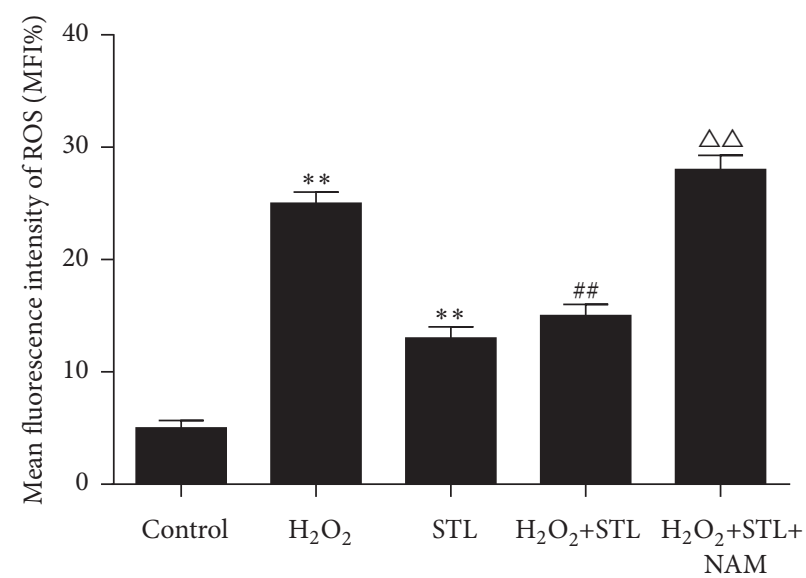

(f)

FiguRE 6: Effect of STL on ROS level in $\mathrm{H}_{2} \mathrm{O}_{2}$-induced injury in BMECs. (a) Control group; (b) $\mathrm{H}_{2} \mathrm{O}_{2}$ group; (c) $\mathrm{H}_{2} \mathrm{O}_{2}+\mathrm{STL}$ (0.025 g/L); (d) $\mathrm{H}_{2} \mathrm{O}_{2}+\mathrm{STL}(0.05 \mathrm{~g} / \mathrm{L}) ;(\mathrm{e}) \mathrm{H}_{2} \mathrm{O}_{2}+\mathrm{STL}(0.1 \mathrm{~g} / \mathrm{L})$. (f) Mean fluorescence intensity of ROS. ${ }^{* *} P<0.01$ compared to control group; ${ }^{\# \#} P<0.01$ compared to $\mathrm{H}_{2} \mathrm{O}_{2}$ group; ${ }^{\triangle \triangle} P<0.01$ compared to $\mathrm{H}_{2} \mathrm{O}_{2}+$ STL group.

with STL decreased p21 protein expression $(P<0.05)$ when compared to the $\mathrm{H}_{2} \mathrm{O}_{2}$ group. Moreover, NAM treatment significantly counteracted the effect of STL $(0.1 \mathrm{~g} / \mathrm{L})$ on lowering p21 protein expression $(P<0.05)$.

\section{Discussion}

The present study suggested that STL could attenuate the pathogenic processes of $\mathrm{H}_{2} \mathrm{O}_{2}$-induced oxidative stress injury in rat brain microvascular endothelial cells (BMECs) by reducing $\mathrm{H}_{2} \mathrm{O}_{2}$-induced increase in the levels of intracellular
ROS and p21 and upregulating $\mathrm{H}_{2} \mathrm{O}_{2}$-induced decline of GSH, SOD, and PGC- $1 \alpha$ via SIRT1/PGC- $\alpha$ and SIRT1/p21 pathway.

Oxidative stress is one of the important factors leading to vascular endothelial dysfunction when endothelial cells are being exposed to excessive production of ROS and affects cell growth and apoptosis of the blood vessel walls [5]. Studies have shown that high levels of free fatty acids induced oxidative stress, which damaged human brain microvascular endothelial cells and resulted in apoptosis [24]. Oxidative stress occurs when the levels of ROS exceed the capacity 

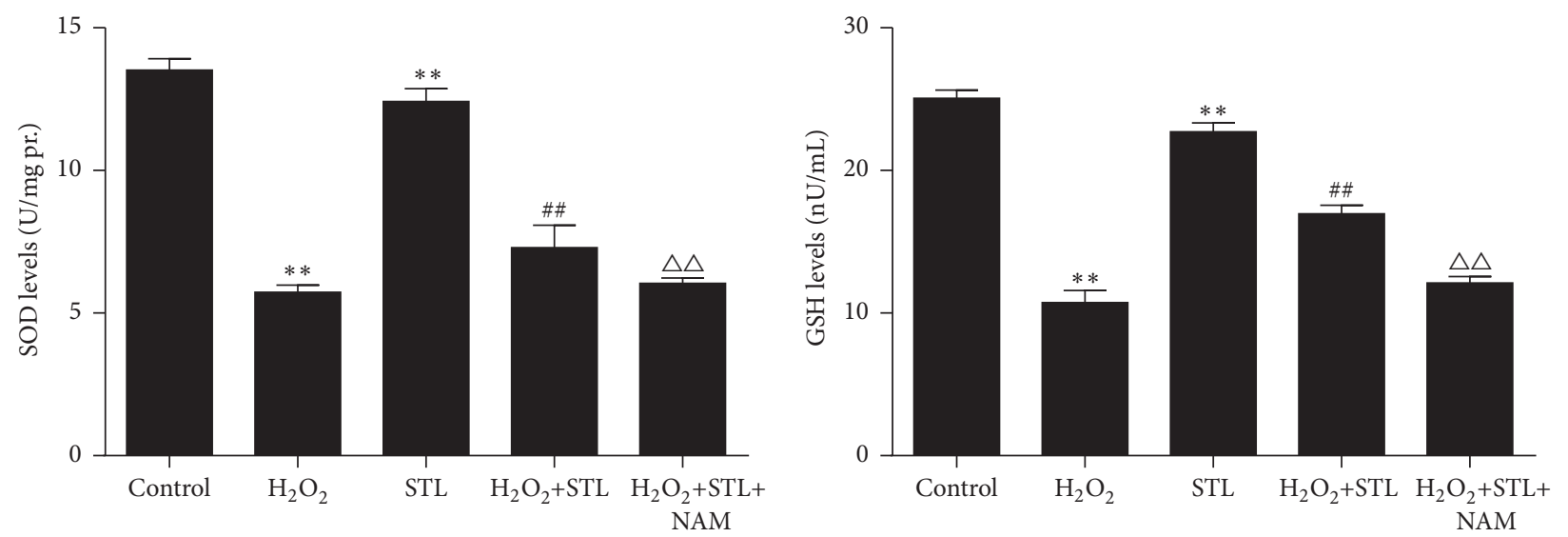

FIGURE 7: Effect of STL on SOD levels in $\mathrm{H}_{2} \mathrm{O}_{2}$-induced injury in BMECs. ${ }^{* *} P<0.01$ compared to control group; ${ }^{\# \#} P<0.01$ compared to $\mathrm{H}_{2} \mathrm{O}_{2}$ group; ${ }^{\triangle \triangle} P<0.01$ compared to $\mathrm{H}_{2} \mathrm{O}_{2}+$ STL group. Effect of STL on GSH levels in $\mathrm{H}_{2} \mathrm{O}_{2}$-induced injury in BMECs. ${ }^{* *} P<0.01$ compared to control group; ${ }^{\# \#} P<0.01$ compared to $\mathrm{H}_{2} \mathrm{O}_{2}$ group; ${ }^{\triangle \triangle} P<0.01$ compared to $\mathrm{H}_{2} \mathrm{O}_{2}+$ STL group.
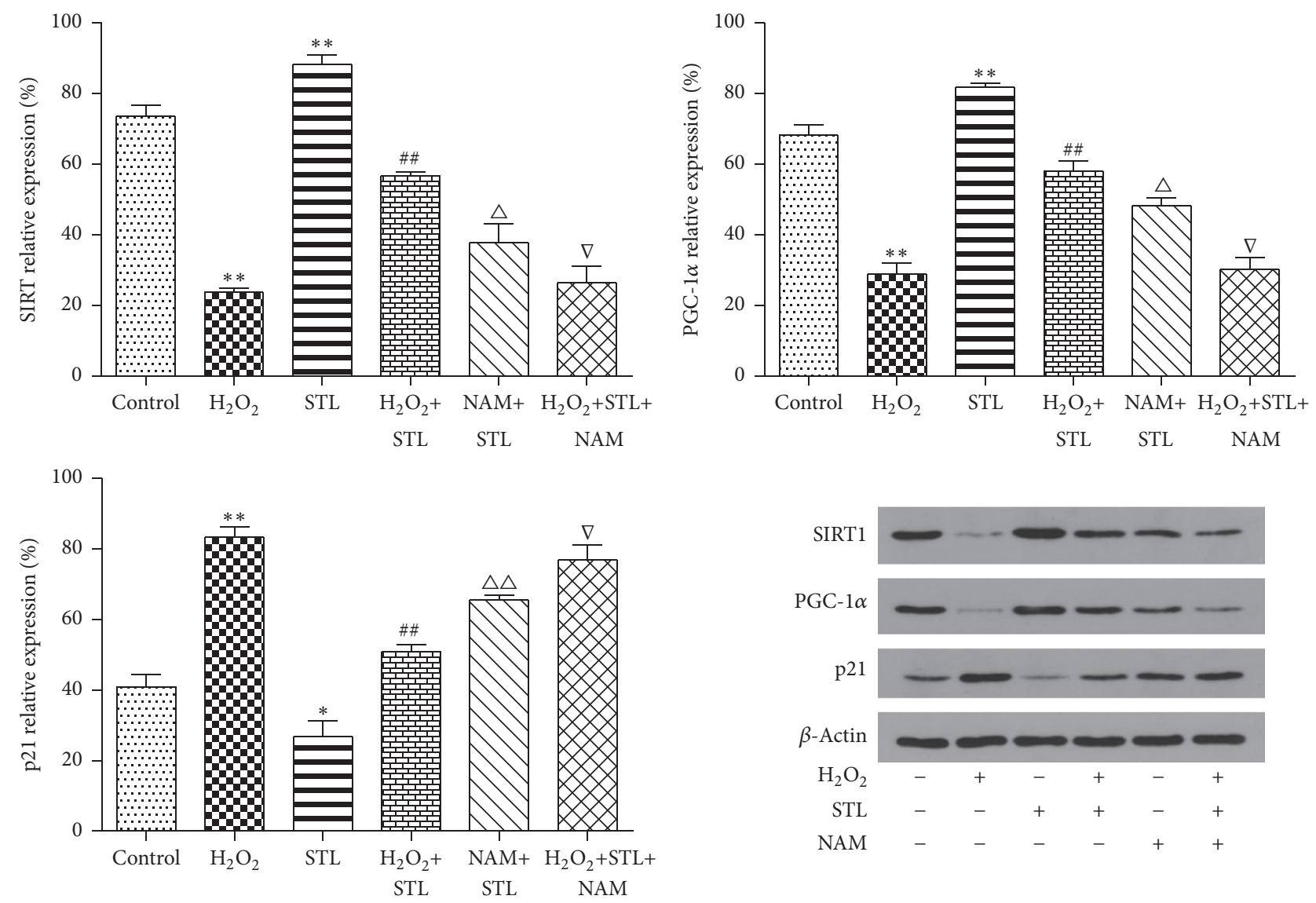

FIGURE 8: Effect of STL on SIRT1 protein expression in $\mathrm{H}_{2} \mathrm{O}_{2}$-induced injury in BMECs. ${ }^{* *} P<0.01$ compared to control group; ${ }^{\# \#} P<0.01$ compared to $\mathrm{H}_{2} \mathrm{O}_{2}$ group; ${ }^{\triangle} P<0.05$ compared to STL group; ${ }^{\nabla} \mathrm{P}<0.05$ compared to $\mathrm{H}_{2} \mathrm{O}_{2}+\mathrm{STL}$ group. Effect of STL on PGC-1 $\alpha$ protein expression in $\mathrm{H}_{2} \mathrm{O}_{2}$-induced injury in BMECs. ${ }^{* *} P<0.01$ compared to control group; ${ }^{\# \#} P<0.01$ compared to $\mathrm{H}_{2} \mathrm{O}_{2}$ group; ${ }^{\wedge} P<0.05$ compared to STL group; ${ }^{\nabla} \mathrm{P}<0.05$ compared to $\mathrm{H}_{2} \mathrm{O}_{2}+$ STL group. Effect of STL on p21 protein expression in $\mathrm{H}_{2} \mathrm{O}_{2}$-induced injury in BMECs. ${ }^{* *} P<0.01,{ }^{*} P<0.05$ compared to control group; ${ }^{\# *} P<0.01$ compared to $\mathrm{H}_{2} \mathrm{O}_{2}$ group; ${ }^{\triangle} P<0.05$ compared to STL group; ${ }^{\nabla} P<0.05$ compared to $\mathrm{H}_{2} \mathrm{O}_{2}+$ STL group. Effect of STL on SIRT1, PGC-1 $\alpha$, and p21 protein expression in $\mathrm{H}_{2} \mathrm{O}_{2}$-induced injury in BMECs. 
of physiological antioxidant defense mechanisms [25]. Thus, overall vascular function is dependent upon the balance of oxidant and antioxidant mechanisms, which determines endothelial function. ROS consist of oxygen free radicals and associated entities that include superoxide free radicals $\left(\mathrm{O}_{2}{ }^{-}\right)$, hydrogen peroxide $\left(\mathrm{H}_{2} \mathrm{O}_{2}\right)$, nitric oxide (NO), and peroxynitrite $\left(\mathrm{OONO}^{-}\right)[4,26,27]$. In general, NADPH oxidase, xanthine oxidase, endothelial nitric oxide synthase (eNOS), lipoxygenases, and myeloperoxidase are the enzymes primarily involved in ROS production. Especially in the vascular system, the vascular production of ROS is mainly driven by the increased activity of the NADPH oxidase isoforms [7]. Endothelial function is usually defined as nitric oxide (NO) production and bioavailability. Because ROS can interact and inactivate $\mathrm{NO}$, vascular oxidative stress can lead to a decrease in NO bioavailability. Furthermore, under the no pathological conditions, eNOS in endothelial cells produces $\mathrm{NO}$ by coupling with a cofactor, tetrahydrobiopterin $\left(\mathrm{BH}_{4}\right)$. Additionally, plasma level of asymmetric dimethylarginine (ADMA), an endogenous competitive inhibitor of NO, is elevated in several diseases, including hypertension, and correlates with the degree of endothelial dysfunction. In summary, excessive ROS accumulated by increased NADPH oxidase can bring about $\mathrm{OONO}^{-}$generation, ADMA inactivation, and tetrahydrobiopterin $\left(\mathrm{BH}_{4}\right)$ oxidation, leading to reduction of $\mathrm{NO}$, and then damage vascular cells [28-30].

SIRT1 is expressed throughout the body, has broad biological effects, and can significantly affect both cellular survival and longevity during acute and long-term injuries, which involve both oxidative stress and cell metabolism [31]. Research has found that SIRT1 can promote lifespan in higher organisms above yeast and metazoans [32], meanwhile promoting the protection of endothelial cells during oxidant stress exposure $[14,15]$. Damaged mitochondria are thought to release more ROS and set in motion a vicious cycle of increasing DNA damage leading to increased ROS production that in turn leads to more DNA damage. Moreover, excessive accumulation of DNA damage will activate p21 and further induce cell senescence [33]. Reactive oxygen species trigger cell aging and regulate senescence-associated genes p16 and p53/p21 $[34,35]$. As p21 genes are the members of the cyclin protein dependent kinase inhibitors family, cell cycle arrest is the precondition of aging, and increased p21 is enough to cause cell aging and has wide application in establishing aging model $[36,37]$. SIRT1 was found to be capable of alleviating the oxidative stress-induced senescence of cartilage end plates cells in humans via downregulation of p53/p21 transcriptional activity [38] and it may be necessary for DNA repair to block apoptotic cell death during both acute injury and aging processes [39]. It is reported that SIRT1 activation can induce PGC- $1 \alpha$ activity by facilitating SIRT1mediated deacetylation and subsequently reduce peroxisome proliferator activated receptor- $\alpha$ (PPAR- $\alpha$ ) activation, which results in downregulation of the NADPH oxidase subunits p22 $2^{\text {phox }}$ and NOX4. SIRT1 hence plays a crucial role in reducing oxygen free radical product of blood vessels and resistance to oxidative stress [40]. PGC- $1 \alpha$ is PPAR- $\alpha$ activated factor, and it can reduce oxygen free radicals induced by NADPH oxidase and increase mitochondrial DNA and raise antioxidant enzymes such as MnSOD and glutathione peroxidase enzyme (GPxl). Histone acetyltransferases compound directly acetylated PGC1- $\alpha$ multiple lysine residues and played a negative role in transcription activity [41]. In summary, SIRT1 activation will help PGC- $1 \alpha$ in acetylation to combine with chromatin and increase the activity of transcription [42]. Therefore, SIRT1/PGC-1 $\alpha$ signaling pathway plays a very important role in cellular defense against oxidative stress.

The origin and development of Chinese traditional medicine were based on the accumulation of lifetimes of experience and practice of the Chinese people to maintain health and treat disease. Chinese medicinal materials or prescriptions had been applied to keep balance of yin-yang and regulate qi and blood for thousands of years [43, 44]. According to the theory of traditional Chinese medicine, vascular encephalopathies, including ischemic stroke, migraine, vascular dementia, and dizziness, were usually attributed to qi deficiency, qi stagnancy, and blood stasis. As previously mentioned, the herbs in STL have the functions of invigorating and promoting qi and blood circulation and relieving depression. We used HPLC to identify the active ingredients and found that STL contained puerarin, astragaloside IV, paeoniflorin, curcumin, and Chikusetsu V. Our previous study showed that puerarin can protect against brain injury by counteracting the inflammatory response after cerebral ischemia/reperfusion via activating the cholinergic anti-inflammatory pathway [45]. Also, puerarin could provide neuroprotection against traumatic brain injury-induced oxidative stress characterized by the severe disturbance of redox balance; puerarin treatment could lead to a significant decrease in the MDA content and increase in the level of GSH in comparison with vehicle treatment after traumatic brain injury, at least in part, through the activation of PI3K-Akt pathway, which may represent a new promising therapeutic agent in the treatment of traumatic brain injury in the future [46]. Another active ingredient, astragaloside IV, had protective effects on focal cerebral ischemia in rats at different reperfusion time points. Astragaloside IV treatment increased SOD activity and decreased the level of MDA at different time points, suggesting that astragaloside IV attenuated lipid peroxidation and reduced the generation of superoxide anions in cerebral ischemia/reperfusion. The mechanism may be related to antioxidation, regulating the expressions of iNOS, NGF, and TrkA mRNA [47]. As an ingredient of STL, paeoniflorin alleviated the acute damage induced by LPS in mice brains, which was related to its antioxidant effect and improvement of energy metabolism, which could reduce the levels of MDA production and significantly increase the activities of antioxidant enzymes such as SOD and GSH-PX; besides, paeoniflorin was able to increase the expression of HO-1 and activate the nuclear transfer of Nrf2 [48]. In addition, study demonstrated that carbofuran at sublethal doses was able to cause oxidative stress damage in the brainstem of rats, with the effect being dose-dependent. But the pretreatment of animals with curcumin showed attenuation of carbofuran toxicity because the activities of SOD and GSH of rat brain were significantly increased. 
The ameliorative effect of curcumin may be mediated via antioxidant potential of this molecule by scavenging the free radicals [17]. Moreover, curcumin treatment at both low and high doses significantly reduced levels of ROS and MDA and enhanced the activity of SOD and GSH-PX compared with the oxyhemoglobin group, and treatment with curcumin at both low and high doses significantly reduced the levels of TNF- $\alpha$, IL-1 $\beta$, and IL- 6 compared with the oxyhemoglobin group, suggesting that curcumin is protective against oxyhemoglobin induced neurotoxicity in an in vitro subarachnoid hemorrhage model and the protective effects of curcumin were mainly dependent on its attenuating oxidative stress, inflammation, and neuronal apoptosis [49]. Additionally, study showed that Chikusetsu V exhibited neuroprotective effects in human neuroblastoma cells by reducing cytotoxicity, scavenging oxygen free radicals, and preventing decline in mitochondrial membrane potential. It is possibly mediated by enforcing endogenous antioxidant gene expressions of SIRT1, PGC-1 $\alpha$, and Mn-SOD. As a result, antioxidant effect may be a major mechanism for Chikusetsu V-mediated neuroprotection and Chikusetsu V could be a candidate for the treatment of oxidative stress-induced neurodegenerative disease [50]. Taken together, these findings help us to enhance our understanding of how fermented STL work.

It is reported that fermentation is a slow decomposition process of organic substances induced by microorganisms. It actively ruptures the cells of herb exposing it more to the menstruum, and bacteria have enzymes that break down cell walls to further assist in the leaching process. Furthermore, fermentation is an energy yielding process in which a nutrient molecule such as glucose is broken down without oxidation [51]. Recent study has shown that fermented Chinese traditional medicine was safe and nontoxic [52], and it can be used for antitumor [53] and antifungal [54] purposes and can improve neuroprotection [55] especially against antioxidative stress [56]. It has been reported that a human umbilical vein endothelial cell (EC) culture system was used to evaluate the effects of the fermented culture broth of a traditional Chinese medicine, Antrodia camphorata (FCBA), against the oxidative cell damage induced by the free radical generator AAPH. FCBA treatment significantly inhibited AAPH apoptotic cell death in the ECs, as evidenced by reducing DNA fragmentation, cytochrome $\mathrm{C}$ release, caspase-3 activation, and dysregulation of $\mathrm{Bcl}-2$ and Bax. Moreover, the AAPH-induced reductions in EC SOD activity and protein levels were prevented by FCBA [56]. These studies suggested that we can improve the antioxidant ability of traditional Chinese medicine via applying fermentation technology.

In summary, using the liquid-state fermentation method, we screened out a new dosage form of Chinese formula called Shuan-Tong-Ling (STL), which was adapted from a classical prescription, Sanpian Decoction, clinically employed to treat migraine and other vascular encephalopathies for hundreds of years in China. In the present study, we have shown that STL had protective effects against oxidative stress injury induced by $\mathrm{H}_{2} \mathrm{O}_{2}$ in BMECs, which may be via regulating SIRT1/PGC- $\alpha$ and SIRT1/p21 signaling pathway.

\section{Competing Interests}

All the authors declare that they do not have any competing interests.

\section{Authors' Contributions}

Lingjing Tan and Xiang Zhang contributed equally to this work.

\section{Acknowledgments}

The present study was supported by Open Fund of Key Laboratory of Cardiovascular and Cerebrovascular Diseases Translational Medicine, China Three Gorges University (2016xnxg101).

\section{References}

[1] K. Maiese, Z. Z. Chong, J. Hou, and Y. C. Shang, "Oxidative stress: biomarkers and novel therapeutic pathways," Experimental Gerontology, vol. 45, no. 3, pp. 217-234, 2010.

[2] D. D. Heistad, "Oxidative stress and vascular disease: 2005 Duff lecture," Arteriosclerosis, Thrombosis, and Vascular Biology, vol. 26, no. 4, pp. 689-695, 2006.

[3] M. F. Beal, "Aging, energy, and oxidative stress in neurodegenerative diseases," Annals of Neurology, vol. 38, no. 3, pp. 357-366, 1995.

[4] F. Santilli, D. D’Ardes, and G. Davì, "Oxidative stress in chronic vascular disease: from prediction to prevention," Vascular Pharmacology, vol. 74, pp. 23-37, 2015.

[5] T. M. Buttke and P. A. Sandstrom, "Oxidative stress as a mediator of apoptosis," Immunology Today, vol. 15, no. 1, pp. 710, 1994.

[6] B. S. Berlett and E. R. Stadtman, "Protein oxidation in aging, disease, and oxidative stress," The Journal of Biological Chemistry, vol. 272, no. 33, pp. 20313-20316, 1997.

[7] K. K. Griendling, D. Sorescu, and M. Ushio-Fukai, "NAD(P)H oxidase: role in cardiovascular biology and disease," Circulation Research, vol. 86, no. 5, pp. 494-501, 2000.

[8] K. Irani, "Oxidant signaling in vascular cell growth, death, and survival: a review of the roles of reactive oxygen species in smooth muscle and endothelial cell mitogenic and apoptotic signaling," Circulation Research, vol. 87, no. 3, pp. 179-183, 2000.

[9] W. M. Pardridge, "The blood-brain barrier: bottleneck in brain drug development," NeuroRx, vol. 2, no. 1, pp. 3-14, 2005.

[10] G. J. Del Zoppo and J. M. Hallenbeck, "Advances in the vascular pathophysiology of ischemic stroke," Thrombosis Research, vol. 98, no. 3, pp. 73-81, 2000.

[11] B. Zschoernig and U. Mahlknecht, "SIRTUIN 1: regulating the regulator," Biochemical and Biophysical Research Communications, vol. 376, no. 2, pp. 251-255, 2008.

[12] M. Potente and S. Dimmeler, "Emerging roles of SIRT1 in vascular endothelial homeostasis," Cell Cycle, vol. 7, no. 14, pp. 2117-2122, 2008

[13] X.-X. Kong, R. Wang, X.-J. Liu et al., "Function of SIRT1 in physiology," Biochemistry, vol. 74, no. 7, pp. 703-708, 2009.

[14] C.-L. Kao, L.-K. Chen, Y.-L. Chang et al., "Resveratrol protects human endothelium from $\mathrm{H}_{2} \mathrm{O}_{2}$-induced oxidative stress and senescence via SirT1 activation, vol. 17, no. 9, pp. 970-979, 2010. 
[15] Z. Song, Y. Liu, B. Hao et al., "Ginsenoside Rb1 prevents $\mathrm{H}_{2} \mathrm{O}_{2}$ induced HUVEC senescence by stimulating sirtuin-1 pathway," PLoS ONE, vol. 9, no. 11, Article ID el12699, 2014.

[16] X. Zhu, K. Wang, K. Zhang, X. Lin, L. Zhu, and F. Zhou, "Puerarin protects human neuroblastoma SH-SY5Y cells against glutamate-induced oxidative stress and mitochondrial dysfunction," Journal of Biochemical \& Molecular Toxicology, vol. 30, no. 1, pp. 22-28, 2016.

[17] S. K. Jaiswal, A. Sharma, V. K. Gupta, R. K. Singh, and B. Sharma, "Curcumin mediated attenuation of carbofuran induced oxidative stress in rat brain," Biochemistry Research International, vol. 2016, Article ID 7637931, 7 pages, 2016.

[18] J. Shen, Y. Zhu, K. Y. Huang et al., "Buyang Huanwu Decoction attenuates $\mathrm{H}_{2} \mathrm{O}_{2}$-induced apoptosis by inhibiting reactive oxygen species-mediated mitochondrial dysfunction pathway in human umbilical vein endothelial cells," BioMed Central Complementary and Alternative Medicine, vol. 16, no. 1, pp. 111, 2016.

[19] M. Ni, Yellow Emperor's Classic of Medicine, Häftad Maoshing $\mathrm{Ni}, 1995$.

[20] L.-D. Zhao, J.-H. Wang, G.-R. Jin, Y. Zhao, and H.-J. Zhang, "Neuroprotective effect of Buyang Huanwu Decoction against focal cerebral ischemia/reperfusion injury in rats-time window and mechanism," Journal of Ethnopharmacology, vol. 140, no. 2, pp. 339-344, 2012.

[21] J.-H. Li, A.-J. Liu, H.-Q. Li, Y. Wang, H.-C. Shang, and G.-Q. Zheng, "Buyang Huanwu Decoction for healthcare: evidencebased theoretical interpretations of treating different diseases with the same method and target of vascularity," Evidence-Based Complementary and Alternative Medicine, vol. 2014, Article ID 506783, 17 pages, 2014.

[22] H. Li, R. J. Li, and F. Li, "Modified Sanpian Decoction in treating migraine randomized controlled clinical study," Journal of Practical Traditional Chinese Internal Medicine, vol. 26, no. 12, pp. 12-13, 2012.

[23] Z. K. Liang, G. Z. Yao, and X. C. Liang, "Analysis on therapeutic effect of migraine treated by Sanpian decoction combined with electro acupuncture," Journal of Practical Traditional Chinese Medicine, vol. 27, no. 6, pp. 366-368, 2011.

[24] H. Zhou, X. Liu, L. Liu et al., "Oxidative stress and apoptosis of human brain microvascular endothelial cells induced by free fatty acids," Journal of International Medical Research, vol. 37, no. 6, pp. 1897-1903, 2009.

[25] M. K. Eskandari, "Oxidative stress and vascular disease," Arteriosclerosis Thrombosis \& Vascular Biology, vol. 34, no. 5, pp. 689-695, 2001.

[26] Z. C. Zhao, F. Li, and K. Maiese, "Oxidative stress in the brain: novel cellular targets that govern survival during neurodegenerative disease," Progress in Neurobiology, vol. 75, no. 3, pp. 207246, 2005.

[27] R. M. Starke, N. Chalouhi, M. S. Ali et al., "The role of oxidative stress in cerebral aneurysm formation and rupture," Current Neurovascular Research, vol. 10, no. 3, pp. 247-255, 2013.

[28] H. Ogita and J. K. Liao, "Endothelial function and oxidative stress," Endothelium, vol. 11, no. 2, pp. 123-132, 2004.

[29] P. M. Vanhoutte, Y. Zhao, A. Xu, and S. W. Leung, “Thirty years of saying NO," Circulation Research, vol. 119, no. 2, pp. 375-396, 2016.

[30] A. Bielli, M. G. Scioli, D. Mazzaglia, E. Doldo, and A. Orlandi, "Antioxidants and vascular health," Life Sciences, vol. 143, pp. 209-216, 2015.
[31] Z. Z. Chong, Y. C. Shang, S. Wang, and K. Maiese, "SIRT1: New avenues of discovery for disorders of oxidative stress," Expert Opinion on Therapeutic Targets, vol. 16, no. 2, pp. 167-178, 2012.

[32] Z. C. Zhao and K. Maiese, "Enhanced tolerance against early and late apoptotic oxidative stress in mammalian neurons through nicotinamidase and sirtuin mediated pathways," Current Neurovascular Research, vol. 5, no. 3, pp. 159-170, 2008.

[33] P. Rai, T. T. Onder, J. J. Young et al., "Continuous elimination of oxidized nucleotides is necessary to prevent rapid onset of cellular senescence," Proceedings of the National Academy of Sciences of the United States of America, vol. 106, no. 1, pp. 169174, 2009.

[34] K.-J. Park, Y.-J. Kim, J. Kim et al., "Protective effects of peroxiredoxin on hydrogen peroxide induced oxidative stress and apoptosis in cardiomyocytes," Korean Circulation Journal, vol. 42, no. 1, pp. 23-32, 2012.

[35] Y. S. Hori, A. Kuno, R. Hosoda, and Y. Horio, "Regulation of FOXOs and p53 by SIRT1 modulators under oxidative stress," PLoS ONE, vol. 8, no. 9, Article ID e73875, 2013.

[36] O. V. Leontieva and M. V. Blagosklonny, “Tumor promoterinduced cellular senescence: cell cycle arrest followed by geroconversion," Oncotarget, vol. 5, no. 24, pp. 12715-12727, 2014.

[37] Y. Hua, T. J. Robinson, Y. Cao, G.-P. Shi, J. Ren, and S. Nair, "Cathepsin K knockout alleviates aging-induced cardiac dysfunction," Aging Cell, vol. 14, no. 3, pp. 345-351, 2015.

[38] N. Zhou, X. Lin, W. Dong et al., "SIRT1 alleviates senescence of degenerative human intervertebral disc cartilage endo-plate cells via the p53/p21 pathway," Scientific Reports, vol. 6, Article ID 22628, 2016.

[39] V. Audrito, T. Vaisitti, D. Rossi et al., "Nicotinamide blocks proliferation and induces apoptosis of chronic lymphocytic leukemia cells through activation of the p53/miR-34a/SIRT1 tumor suppressor network," Cancer Research, vol. 71, no. 13, pp. 4473-4483, 2011.

[40] M. Lagouge, C. Argmann, Z. Gerhart-Hines et al., "Resveratrol improves mitochondrial function and protects against metabolic disease by activating SIRT1 and PGC- $1 \alpha$," Cell, vol. 127, no. 6, pp. 1109-1122, 2006.

[41] C. Lerin, J. T. Rodgers, D. E. Kalume, S.-H. Kim, A. Pandey, and P. Puigserver, "GCN5 acetyltransferase complex controls glucose metabolism through transcriptional repression of PGC1 $\alpha$," Cell Metabolism, vol. 3, no. 6, pp. 429-438, 2006.

[42] Z. Gerhart-Hines, J. T. Rodgers, O. Bare et al., "Metabolic control of muscle mitochondrial function and fatty acid oxidation through SIRT1/PGC-1 $\alpha$," The EMBO Journal, vol. 26, no. 7, pp. 1913-1923, 2007.

[43] J.-T. Cheng, "Review: drug therapy in Chinese traditional medicine," Journal of Clinical Pharmacology, vol. 40, no. 5, pp. 445-450, 2000.

[44] B. Y. K. Law, S. W. F. Mok, A. G. Wu, C. W. K. Lam, M. X. Y. Yu, and V. K. W. Wong, "New potential pharmacological functions of Chinese herbal medicines via regulation of autophagy," Molecules, vol. 21, no. 3, p. 359, 2016.

[45] X. J. Liu, Z. G. Mei, J. P. Qian, Y. B. Zeng, and M. Z. Wang, "Puerarin partly counteracts the inflammatory response after cerebral ischemia/reperfusion via activating the cholinergic anti-inflammatory pathway," Neural Regeneration Research, vol. 8, no. 34, pp. 3203-3215, 2013.

[46] J.-W. Wang, H.-D. Wang, Z.-X. Cong et al., "Puerarin ameliorates oxidative stress in a rodent model of traumatic brain injury," Journal of Surgical Research, vol. 186, no. 1, pp. 328-337, 2014. 
[47] C. Xu, F. Tang, M. Lu et al., "Astragaloside IV improves the isoproterenol-induced vascular dysfunction via attenuating eNOS uncoupling-mediated oxidative stress and inhibiting ROS-NF- $\kappa \mathrm{B}$ pathways," International Immunopharmacology, vol. 33, pp. 119-127, 2016.

[48] L. Liu, X.-J. Qiu, S.-N. He, H. Yang, D. Wang, and X.-M. Yang, "Effect of paeoniflorin on oxidative stress and energy metabolism in mice with lipopolysaccharide (LPS)-induced brain injury," China Journal of Chinese Materia Medica, vol. 40, no. 14, pp. 2871-2875, 2015.

[49] X. Li, L. Zhao, L. Yue et al., "Evidence for the protective effects of curcumin against oxyhemoglobin-induced injury in rat cortical neurons," Brain Research Bulletin, vol. 120, pp. 34-40, 2016.

[50] J. Wan, L. Deng, C. Zhang, L. L. Deng et al., "Chikusetsu saponin $\mathrm{V}$ attenuates $\mathrm{H}_{2} \mathrm{O}_{2}$-induced oxidative stress in human neuroblastoma SH-SY5Y cells through Sirt1/PGC-1 $\alpha / \mathrm{Mn}-\mathrm{SOD}$ signaling pathways," Canadian Journal of Physiology \& Pharmacology, vol. 49, no. 9, pp. 919-928, 2016.

[51] S. Mulay and A. Khale, "ASAVARISHTAS through improved fermentation technology," International Journal of Pharmaceutical Sciences Research, vol. 2, no. 6, pp. 1421-1425, 2011.

[52] H. Park, Y.-H. Hwang, H. J. Yang, H.-K. Kim, K. S. Song, and J. Y. Ma, "Acute toxicity and genotoxicity study of fermented traditional herb formula Guibi-tang," Journal of Ethnopharmacology, vol. 156, pp. 182-189, 2014.

[53] S.-L. Li, Z.-N. Huang, H.-H. Hsieh et al., "The augmented antitumor effects of Antrodia camphorata co-fermented with Chinese medicinal herb in human hepatoma cells," The American Journal of Chinese Medicine, vol. 37, no. 4, pp. 771-783, 2009.

[54] S. Kuwaki, I. Ohhira, M. Takahata, Y. Murata, and M. Tada, "Antifungal activity of the fermentation product of herbs by lactic acid bacteria against tinea," Journal of Bioscience \& Bioengineering, vol. 94, no. 5, pp. 401-405, 2002.

[55] H. J. Yang, J. B. Weon, B. Lee, and C. J. Ma, "The alteration of components in the fermented Hwangryunhaedok-tang and its neuroprotective activity," Pharmacognosy Magazine, vol. 7, no. 27, pp. 207-212, 2011.

[56] Y.-C. Hseu, S.-C. Chen, Y.-J. Yech, L. Wang, and H.-L. Yang, "Antioxidant activity of Antrodia camphorata on free radicalinduced endothelial cell damage," Journal of Ethnopharmacology, vol. 118, no. 2, pp. 237-245, 2008. 


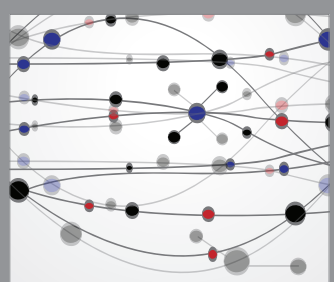

The Scientific World Journal
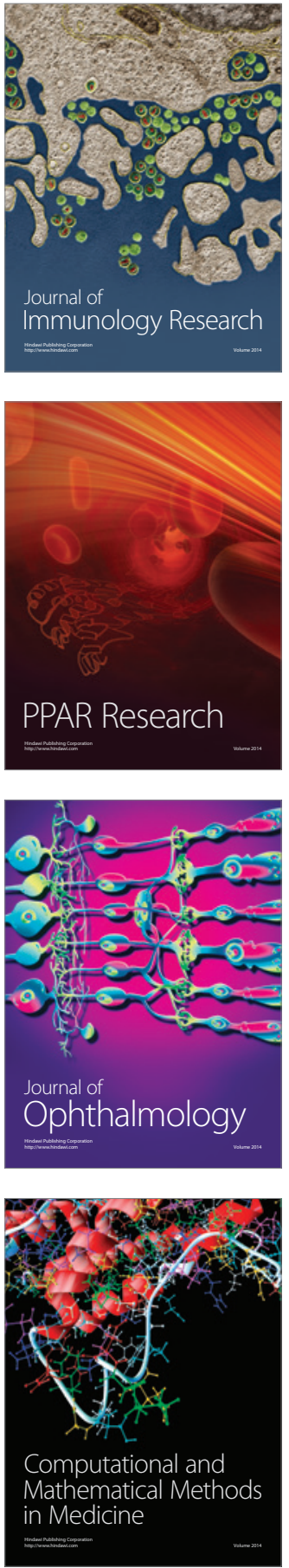

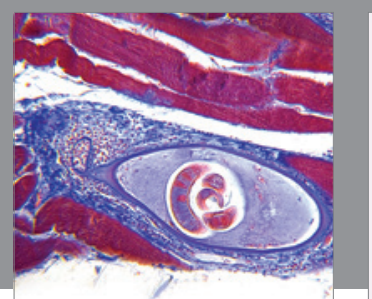

Gastroenterology Research and Practice

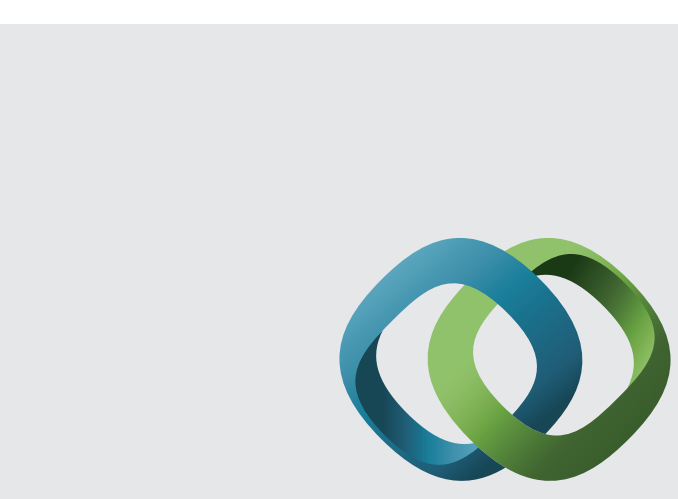

\section{Hindawi}

Submit your manuscripts at

http://www.hindawi.com
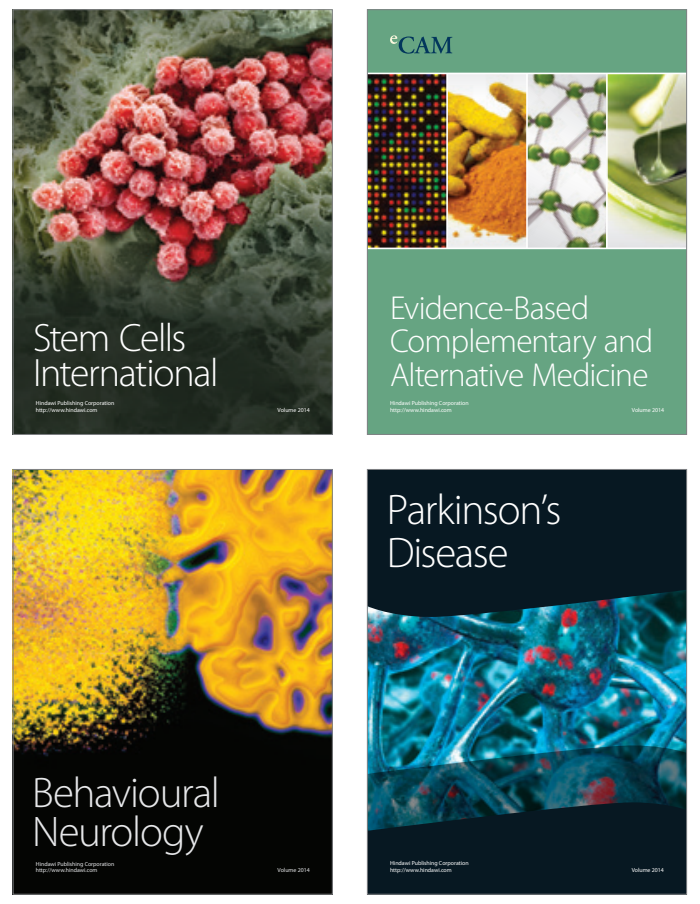
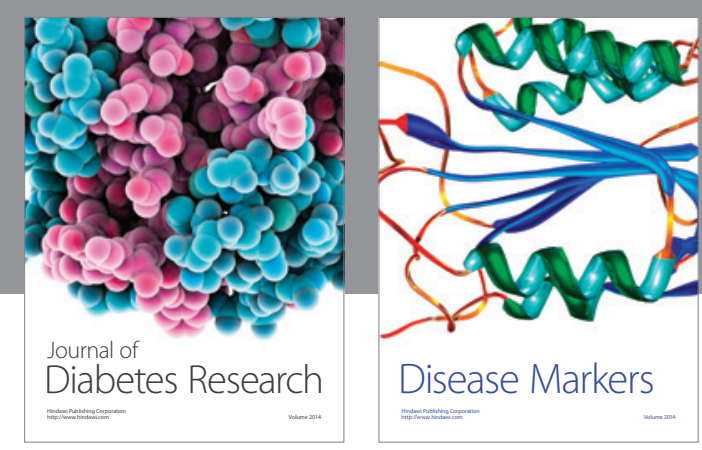

Disease Markers
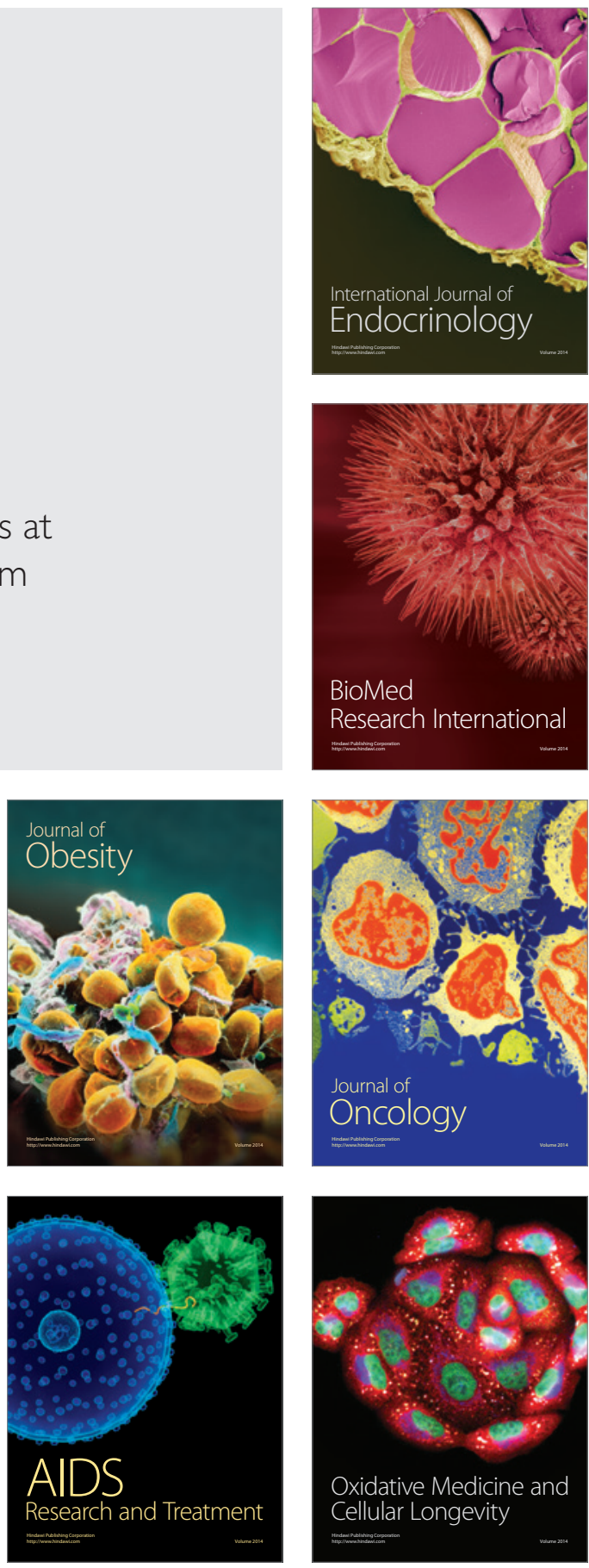